\title{
La riqueza de la flora colombiana
}

\author{
Richard Evans Schultes
}

Rev. Acad. Colomb. Cienc. Ex. Fis. Nat. 1951, 9 (30): 230-242.

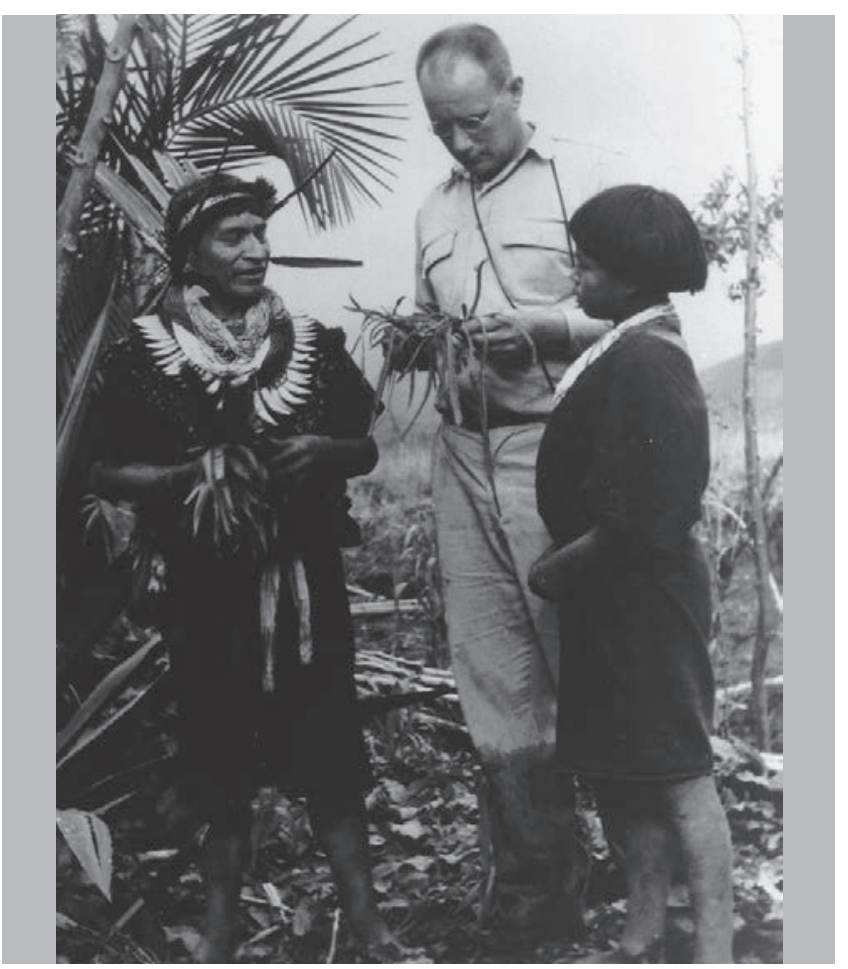

\section{Richard Evans Schultes (1915-2001)}

Llegado a la botánica a través de Richard Spruce, materializó sus sueños con el apoyo del orquideólogo Oakes Ames, quien le acercó a las plantas sagradas de los indígenas. Visitó profusamente (1941-1953) la Amazonía colombiana y entabló una sólida colaboración con el Instituto de Ciencias (UN) y sus botánicos. Realizó importantes recolecciones e investigaciones sobre varios géneros de plantas útiles y medicinales (caucho, curare, yoco, yajé), y, además, describió numerosas especies nuevas. Se amoldó a la realidad académica de Colombia, participó en ella y en 1953 recibió la distinción de Profesor Honorario de la Universidad Nacional. Logró conocer en detalle muchas de las plantas mágicas de las comunidades indígenas amazónicas de Colombia y, en cierto modo, sentó las bases de la moderna etnobotánica. Publicó obras importantes en este campo y se esforzó por mostrar la maravillosa diversidad biológica y etnográfica de la Amazonía colombiana, a la vez que alertaba sobre el riesgo de transformar y perder este patrimonio.
Richard Evans Schultes se nos presenta como un testigo externo y cualificado para hablar de la riqueza de la flora colombiana. En un análisis cuidadoso recorre la historia botánica de Colombia y hace énfasis sobre la escasez de estudios sistemáticos publicados hasta la primera mitad del siglo XX. Muestra con gran nitidez este período crítico en el que se fundaron herbarios, institutos y revistas en favor de la institucionalización de la botánica y de la academia en Colombia, logros asociados a protagonistas como Pérez Arbeláez, Cuatrecasas, Alvarez Lleras y Dugand. También dio cuenta del desarrollo del Herbario Nacional y se preguntó por el número de especies que realmente componen la Flora de Colombia. Para Schultes, Colombia posee la flora más diversa del Neotrópico y la mayor variedad de biomas y dio sólidos argumentos al respecto. Sin descuidar a Mutis y a Triana se centró en el período floreciente que él mejor conoció, al detallar familias y géneros que habían sido estudiados por los diferentes especialistas (compuestas, gramíneas, leguminosas, otras) y se refirió al incremento de especies según intervalos de años. También cotejó el trabajo de Martius y de Spruce con el de sus recientes exploraciones en la Amazonía colombiana. Acudió, asimismo, a la opinión experta de colegas como Cuatrecasas, Dugand y Standley, y con pulcritud matemática, comparó cifras de pliegos, especies, tiempos y áreas, para sustentar su propia estimación de las especies de fanerógamas que crecen en Colombia que el cifra en 50.000 taxones. Concluye su escrito al citar de nuevo a Spruce y trata de estimular la exploración y estudio de las selvas colombianas. Schultes dedica este brillante trabajo "al éxito del III Congreso Sudamericano de Botánica que tendrá lugar en Bogotá en el año 1953”, que con esmero preparaba E. Pérez Arbeláez y que fuera inexplicablemente suspendido por motivos aparentemente políticos.

José Luis Fernández Alonso, Ph. D.

Real Jardín Botánico - CSIC

Miembro Correspondiente 


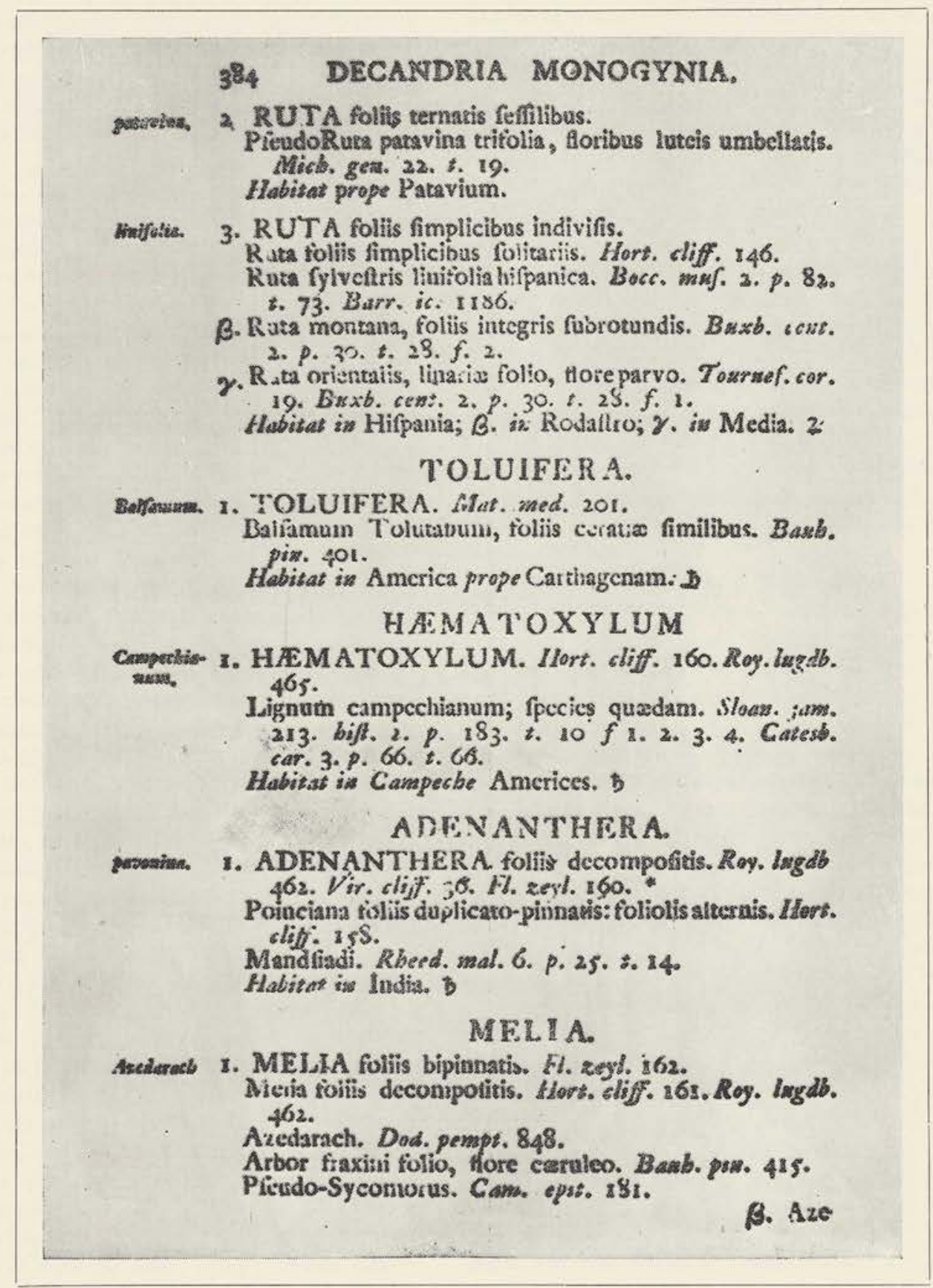

La primera planta colombiana tratada en el sistema binomial de nomenclatura botánica fue el famoso bálsamo del Tolú. Esta especie fue bautizada por el fundador de la botánica moderna, Carlos Linneo, en el primer tomo de su obra "Species Plantarum" de 1753, a base de material originario de la costa atlántica de Colombia, no lejos de Cartagena. 


\section{LA RIQUEZA DE LA FLORA COLOMBIANA}

RICHARD EVANS SCHULTES (1)

"La flora de un país, y especialmente tan extenso y rico como Colombia, no puede ser obra de un hombre ni de un sabio, sino de una generación de sabios y exploradores". (Santiago Cortés: prólogo de la "Flora de Colombia").

Dedico este artículo al éxito del III Congreso Sudamericano de Botánica que tendrá lugar en Bogotá en el año de 1958.

Probablemente son muy pocos los colombianos y los extranjeros residentes en este país que se dan cuenta cabal de la inmensa riqueza y variedad de la flora de Colombia. Esta riqueza es tan asombrosa que se manifiesta claramente ante cualquier observador a primera vista; pero ocurre que raras veces damos importancia a lo que nos rodea, aunque sean maravillas, porque ya estamos acostumbrados a verlas a diario y las tenemos por cosa común y ordinaria.

Aunque Colombia goza de una tradición botánica antigua, que arranca desde los días de Mutis, Valenzuela y Caldas - contemporáneos de la fecunda época linneana en la que se fundó la botánica sistemática moderna- y a pesar de que muchos y renombrados naturalistas (Jacquin, Humboldt, von Martius, Goudot, Triana, Karsten, Linden, André, Lehmann, Purdie y muchos otros) engrandecieron la historia botánica del país, podemos decir que ha sido solamente en los últimos doce años cuando el estudio serio y sistemático de la flora colombiana ha tenido mayor impulso por parte de botánicos colombianos. En la actualidad asistimos a un nuevo y feliz renacimiento de la ciencia botánica en Colombia y se halla en plena marcha el arduo y dilatado trabajo de inventariar la flora de la República y de estudiarla en sus relaciones ecológicas y fitogeográficas.

Esta actividad tan especializada no es cosa espontánea ni superficial sino el resultado de hechos bien meditados y dirigidos por las esferas científicas del país. El período moderno de que estamos tratando comenzó, se puede decir, con la celebración del segundo centenario de Mutis en 1932. En aquel año vino a Colombia, invitado por el gobierno de este país, el doctor José Cuatrecasas, del Jardín Botánico de Madrid, quien realizó excursiones en varias partes del territorio colombiano, recolectando centenares de ejemplares de plantas. Con la publicación en España de los resultados de sus colecciones y estudios, Cuatrecasas dejó en su "Observaciones Geobotánicas en Colombia" un impulso de inestimable valor para futuras investiga-

(1) Botanist, Bureau of Plant Industry, Solls, and Agricultural Engineering, Agricultural Research Administration, United States Departament of Agriculture; Research Fellow, Botanical Museum, Harvard University. ciones fundamentales. Vino otra vez el doctor Cuatrecasas en el año de 1939 para establecerse en Colombia. Durante el mismo período se fundó la lujosa Revista de la Academia Colombiana de Ciencias Exactas, Físico-Químicas y Naturales, publicación en que han aparecido numerosos y valiosos trabajos sobre cuestiones botánicas colombianas. Esta revista, colocada en un nivel científico muy alto por su antiguo director, el doctor Jorge Alvarez Lleras, expresidente de la Academia Colombiana de Ciencias, ha llevado al mundo entero el producto de las labores científicas colombianas en forma digna de su seriedad y de su importancia. Muchas son las nuevas especies de plantas que se han descrito en sus páginas.

En el año de 1938, con ocasión del cuarto Centenario de Bogotá - y gracias a los meritorios esfuerzos del doctor Enrique Pérez Arbeláez- se fundó el Instituto Botánico, que hoy se denomina Instituto de Ciencias Naturales porque comprende también otras ramas de investigación, fuera de la botánica. Este importante centro científico pertenece a la Universidad Nacional y contó hasta hace poco con la ayuda del Ministerio de Agricultura. El Instituto encabeza casi todas las investigaciones botánicas y zoológicas que se desarrollan hoy en Colombia. El corazón de su Sección de Botánica es el Herbario Nacional Colombiano, el cual, aunque existía antes de fundarse el Instituto, sólo fue en 1940 cuando se le dio una orientación moderna y una organización verdaderamente sistemática. Fue entonces cuando botánicos colombianos iniciaron publicaciones científicas, basadas en estudios originales hechos en dicho herbario. Desde su iniciación hasta el presente, cuenta el Herbario Nacional con la colaboración del señor Hernando García-Barriga, uno de los más activos coleccionadores de plantas $y$ estudiante de la flora medicinal y forrajera de Colombia.

La influencia que el Instituto de Ciencias Naturales ejerce en la orientación de nuestros estudios y el aumento de nuestros conocimientos sobre la fauna y la flora de Colombia es decisiva; y su importancia en el desarrollo de la investigación botánica y zoológica en el país es realmente trascendental.

El profesor Armando Dugand, director del Instituto desde 1940, fundó hace diez años, y desde entonces la dirige y edita personalmente, la revista Caldasia, en honor de Francisco José de Caldas, el primer gran naturalista y físico colombiano (1771-1816). Esta revista, hoy en su quinto volumen, ha aparecido con regularidad - aún durante el difícil período de la guerra- y lleva al mundo 
científico entero contribuciones muy valiosas para el mejor conocimiento de la flora y la fauna colombianas y de la región neotropical en general. En las páginas de Caldasia se han publicado ya las descripciones de cinco géneros y 350 especies y variedades de plantas que hasta entonces eran totalmente desconocidas para la ciencia; y además, se han dado informaciones técnicas de primera mano acerca de varios centenares de especies que sólo se conocían de manera muy superficial o de cuyos caracteres o distribución geográfica apenas se tenían nociones incompletas y en algunos casos erróneas.

El Herbario Nacional cuenta hoy con cerca de 35.000 ejemplares de plantas debidamente disecadas $\mathrm{y}$ clasificadas, incluyendo unos 1.250 tipos 0 isotipos taxonómicos, es decir, especímenes seleccionados en los cuales se basan descripciones técnicas de especies nuevas para la ciencia. Están representadas ya unas 10.300 especies diferentes de plantas de Colombia. La labor de aumentar y mejorar el Herbario Nacional sigue una marcha ascendente gracias al esfuerzo constante de todos los profesionales y funcionarios de la Sección de Botánica del Instituto y con la ayuda de varios científicos del exterior.

Hace unos siete años, preocupado el profesor Dugand por la falta de personal colombiano adecuadamente preparado para las labores de investigación de la flora de este país, y temeroso de que esa carencia pudiera algún día ser la causa de que se interrumpieran o suspendieran lamentablemente las labores del Instituto, bregó hasta obtener que la Universidad Nacional creara un curso especial de Botánica Sistemática destinado a la formación del personal idóneo que pudiera continuar con éxito esas labores en el futuro. Creado el curso, el profesor Dugand se hizo cargo de él como catedrático y hace cinco años tuvo la satisfacción de graduar a los primeros botánicos, varios de los cuales prestan ahora sus servicios muy eficaces al Instituto. Dos de éstos, los doctores Jesús M. Idrobo y Alvaro Fernández, inmediatamente después de graduarse obtuvieron beca de la Universidad Nacional para perfeccionar estudios en los Estados Unidos, donde permanecieron dos años.

El desarrollo del Instituto de Ciencias Naturales ha sido tánto, que el edificio que ocupa desde 1938 ha resultado por demás estrecho e inadecuado y ha sido necesario construír otro, mejor planeado y de mayor capacidad, cuya primera planta será terminada a mediados de 1951. Característica importante en el planeamiento de este nuevo hogar de la botánica colombiana es la previsión que se ha tenido para facilitar ensanches aún mayores en el futuro. Terminado, será uno de los mejores edificios para Ciencias Naturales en la América Latina.

Además de las actividades botánicas del Instituto de Ciencias Naturales, la Universidad Nacional fomenta investigaciones sobre la flora de Colombia en la Facultad Nacional de Agronomía de Medellín. También existe un Herbario en esa Facultad, a cargo del botánico doctor Gabriel Gutiérrez, quien también se adiestró en el Instituto de Ciencias Naturales de Bogotá. Se hacen allá colecciones de plantas principalmente de las distintas regiones de Antioquia. El doctor Carlos Madrid, actual Decano de la Facultad, se ha mostrado muy interesado en adelantar todas las ramas de la botánica. En la Revista de la Facultad Nacional de Agronomía, se han publicado varios interesantes artículos de indole especialmente de botánica económica y, con el ensanche del edificio de la Escuela de Biología Vegetal, hay toda probabilidad de que se incrementen las investigaciones que se realizan allá sobre la flora.

Durante varios años en el decenio pasado, el Departamento de Agricultura del Valle del Cauca tenía una Comisión de Botánica muy activa. Sus principales promotores eran el doctor Ciro Molina Garcés y sus colegas. El doctor Cuatrecasas se encargó entonces de coleccionar intensivamente en el Departamento del Valle, especialmente en la región de la Costa del Pacífico y formó un Herbario importante en la Escuela de Agronomía de Cali (que funciona hoy en Palmira y depende de la Universidad Nacional).

Durante la guerra pasada permanecieron largo tiempo en Colombia varios botánicos e ingenieros forestales norteamericanos desempeñando comisiones oficiales dedicadas a conseguir productos vegetales necesarios para el esfuerzo bélico, tales como la quina, el caucho y el barbasco. Muchos de estos científicos hicieron colecciones de la flora en general en varias partes del territorio colombiano, las cuales se están incorporando poco a poco al Herbario Nacional a medida que van siendo estudiadas críticamente por especialistas. Además, algunos de aquellos investigadores extranjeros se han interesado de manera particular y activa en la vegetación de Colombia $\mathrm{y}$ siguen desarrollando su especialidad en este campo, lo cual constituya una herencia sumamente afortunada de aquellos días de confusión de la guerra.

Con actividades tan vigorosas encaminadas a adelantar el estudio de la flora del país, es claro que cada día son más y más las personas que sienten interés creciente por conocer lo que posee Colombia en cuanto a riquezas vegetales. ¿A qué número alcanzará el inventario de las especies de plantas que crecen dentro de los límites del país? Para saberlo hay que hacer el censo de la flora, trabajo que solamente se puede llevar a cabo con garantía de buen éxito si de él se hace cargo un cuerpo de especialistas bien preparados que se dediquen con ahinco y perseverancia al estudio de la vegetación durante muchos años, efectuando exploraciones dilatadas a distintas regiones del país y haciendo estudios minuciosos de los ejemplares y datos que se recojan en esas exploraciones. 
Colombia, en mi concepto, posee la flora más rica de todo el Nuevo Mundo, tanto por el número de especies como por la diversidad de ecología; y no me sorprendería de ningún modo que tuviera mayor número de plantas fanerógamas en relación a su superficie que eualquier otro país del mundo. Naturalmente es imposible calcular todavía con exactitud el número total de especies que existen en el territorio colombiano, pero todos los botánicos colombianos y extranjeros que han venido trabajando por varios años en el estudio de la flora de este país, sienten tarde o temprano la tentación de arriesgar un concepto en este sentido. Yo creo que no es aventurado hacerlo. Con la experiencia que resulta de toda una vida de estudios íntimos de las diversas vegetaciones, el botánico adquiere cierto conocimiento intuitivo de lo que pueden ser la composición y la riqueza de una flora que se está estudiando. La combinación de la experiencia propia con la que otros colegas han adquirido, añadiendo lo que se conoce acerca de la composición de la flora de otros países mejor estudiados botánicamente, permitirán emitir un concepto con bases bastante firmes.

En Madrid se conservan los preciosos e incomparables dibujos de la famosa "Expedición Botánica al Nuevo Reino de Granada" que funcionó en este país en el período de 1783 a 1810, dirigida por el ilustre sabio José Celestino Mutis hasta su muerte (1808) y después por su sobrino, Sinforoso $\mathrm{Mu}$ tis. Aunque la "Expedición Botánica" se limitó casi exclusivamente a las partes andinas e interandinas centrales de lo que es hoy la República de Colombia, la colección iconográfica comprende unas 6.900 láminas que representan cerca de 2.800 especies distintas. Verdaderamente hay que reconocer que semejante labor pictórica, realizada hace ya más de un siglo y medio con un objeto esencialmente científico, no tiene par en el mundo. La minuciosidad de los detalles en cada dibujo y la perfección de sus colores arrancaron el elogio de hombres de ciencia tan célebres como el Barón de Humboldt. Como bien lo dice el profesor Armando Dugand, las láminas de la Expedición Botánica son "una maravilla artística dentro de la Botánica y una maravilla botánica dentro del Arte".

En el "Prodromus Florae Novo-Granatensis", publicado a mediados del siglo pasado, el insigne botánico colombiano José Jerónimo Triana y el francés J. E. Planchon, enumeraron detalladamente unas 1.025 especies y muchas variedades de plantas colombianas; pero aún el área geográfica abarcada por este estudio es muy reducida en relación con la superficie total del país. El herbario que Triana coleccionó en Colombia de 1851 a 1856 alcanzó a unos 4.000 ejemplares, y como la mayoría de ellos representa una sola especie, puede decirse que en ese herbario están representadas unas 3.000 especies diferentes. El Instituto de Ciencias Naturales de la Universidad Nacional ha puesto uno de sus mayores cuidados en este histórico herbario y con mucha paciencia ha logrado salvar de la total destrucción una buena parte de los 3.960 ejemplares que Triana entregó por inventario al gobierno de la Nueva Granada en julio de 1856, y que rodaron de desván en desván y aún en sótanos húmedos sin protección alguna durante ochenta años. Es lamentable que numerosos ejemplares del mayor interés científico - por ser isotipos de especies descritas por Triana y Planchon o por otros botánicos de fama mundial- se perdieron por completo durante ese tiempo por la acción funesta de los insectos, debido al total abandono en que se les tuvo.

Otra obra de índole florística relacionada con Colombia fue la que apareció a fines del siglo pasado con el nombre de "Flora de Colombia", por Santiago Cortés, y de la cual hay una segunda edición publicada en el segundo decenio del siglo en curso. Aunque no se trata de un estudio sistemático de la flora de Colombia, sino más bien de una recopilación de datos diversos, hecha muchas veces sin discriminación crítica, esta obrita sencilla y elemental sirvió para enfocar aún más la atención de los colombianos hacia la riqueza del reino vegetal en su territorio, particularmente en lo que se refiere a las propiedades medicinales, aromáticas, tintóreas, etc., de las plantas. Dice Cortés en el prólogo de su libro que "en (su) obra extensa se hallan las 10.000 especies descritas..." pero lo cierto es que en su "Flora de Colombia" se mencionan en forma muy abreviada un número muchísimo menor de plantas.

Desde el "Prodromus F'lorae Novo-Granatensis" de Triana y Planchon (1862) para acá no ha aparecido un solo libro dedicado a catalogar en forma de inventario sistemático la composición de la cubierta vegetal del país. Esto se debe sin duda alguna a que cada día viene siendo más claro a los botánicos el hecho de que la flora de Colombia es algo tan abundante y complejo que sólo después de mucho trabajo podrá realizarse un censo aún parcial de las vastas y diferentísimas extensiones geográficas de este país, el cual sin duda alguna es el más estratégicamente situado respecto de la flora de todo el continente americano. Con todo, especialistas en varias familias de plantas han tratado en recientes años de presentar monografías que comprenden inventarios bastante exactos y minuciosos de ciertos grupos vegetales colombianos importantes. Estas obras sirven para poder comparar el número de especies colombianas con el número de especies de la misma familia que existen en otros países de condiciones geográficas semejantes. Un ejemplo: el doctor Paul C. Standley, del Chicago Natural History Museum, publicó varias obras sobre una familia de plantas en la que él se especialiź́ - las Rubíáceas (a la que pertenecen el cafeto $\mathrm{y}$ el árbol de quina)-. En su "The Rubiaceae of Colombia" dice el doctor Standley que estas plantas están "excepcionalmente bien representadas" en 
Colombia, con "un mayor número de especies quizás que cualquier otro país de las Américas con la sola excepción del Brasil". En dicha obra, publicada hace ya veintiún años, el doctor Standley preveé que nuevas exploraciones aumentarán en forma apreciable el inventario colombiano de la familia y así precisamente ha sucedido. Standley enumeró 456 especies en el año de 1930 y yo no tengo la menor duda de que hoy podríamos contar con unas 550. El doctor Henri Pittier y sus colegas han enumerado en su "Catálogo de la Flora Venezolana" casi 500 especies y variedades de Rubiáceas en aquel país, y es indudable que la flora de Colombia es más rica y variada que la de Venezuela.

Otro ejemplo: Colombia es muy rica en especies de Pasifloráceas (a la que pertenecen la curuba, la badea, la granadilla). En el año de 1873 Triana y Planchon enumeraron unas 66 especies. Sesenta años más tarde, en 1938, el doctor Ellsworth P. Killip señaló en Colombia 104 especies y variedades en su "American Passifloraceae". Del Perú se conocen 68 y de Venezuela 43. Como en las Américas hay 355 especies, se ve que Colombia, centro de diversificación de esta familia, cuenta con poco menos del $30 \%$ del número total de especies en el Nuevo Mundo.

Hay algunas familias de plantas sumamente bien representadas en Colombia, $y$, aunque muchas veces no puede hacerse un cálculo exacto del número de especies que las componen, debemos llamar la atención hacia la muy notable diversidad con que se presentan en la flora. Por ejemplo, las Compuestas (a la que pertenecen el girasol y los frailejones) son extremadamente numerosas en todo el país, sobre todo en las faldas de los Andes. Muchas son las especies de Leguminosas (familia del fríjol, el guamo, el guandú, los búcaros o chochos) especialmente en las inmensas selvas de la Costa del Pacífico, del Chocó; y las que bordean los grandes ríos que van hacia el Orinoco y el Amazonas, lo mismo que en los bosques semiáridos de la Costa del Caribe. Un botánico brasileño de renombre mundial como especialista en la flora amazónica, el doctor Adolfo Ducke, señala 867 especies de Leguminosas - la mayoría árboles de gran porte- para la Amazonía del Brasil (As Leguminosas da Amazônia Brasileira, $2^{\text {a }}$ edición revisada y aumentada, diciembre de 1949 , p. 14) y es perfectamente seguro que una proporción muy considerable de este número se encuentra también en la adyacente Amazonía Colombiana, no sólo por el mero hecho de la proximidad territorial sino porque se sabe que las leguminosas van aumentando en número de especies a medida que se va desde el oriente hacia el occidente en el valle amazónico.

Colombia es mundialmente conocida como "País de las Orquídeas" y en realidad lo es, aunque todavía está por iniciarse el estudio general y sistemático de las orquídeas colombianas. el doctor Charles Schweinfurth, de la Univesridad de Harvard, me escribe que el orquidiólogo alemán, Rudolf Schlechter, señaló para Colombia 1.293 especies de esta familia y para el Perú 838 en los primeros años del siglo actual. Schweinfurth, que está preparando una obra sobre las orquídeas del Perú, reconoce más de 925 especies en aquel país, lo cual representa un aumento apreciable. Acerca de las orquídeas de Colombia me dice: "Yo creo que Colombia tendrá un número muy superior, por el hecho de que posee muchas especies de la América Central". De Costa Rica, tan pequeña con relación a Colombia, se conocen nada menos que 950 especies.

Podríamos seguir enumerando otras familias abundantes, tales como las Gramíneas, a la que pertenecen las gramas, pastos, gramalotes, como el kikuyo, yaraguá, paja de guinea, etc., pero nos contentamos con los ejemplos ya citados.

Tienen interés para nuestro tema no sólo las familias muy abundantes en número de especies, sino también los grupos de plantas más pequeños; que no por lo pequeños dejan de ser muy interesantes en el estudio de la flora. La riqueza de la flora colombiana se aprecia probablemente con claridad mucho mayor si pasamos revista al adelanto espectacular que nuestro conocimiento de ciertos grupos ha tenido durante los últimos diez o doce años apenas. Tal ha sido este progreso que hoy podemos darnos cuenta de que todas las nociones botánicas adquiridas en tiempos pasados en Colombia eran muy inadecuadas. Podemos ver también cómo los esfuerzos actuales y bien dirigidos de los botánicos, tanto colombianos como los extranjeros que se ocupan de la flora de Colombia, y las exploraciones metódicas que se han efectuado nos han proporcionado conceptos muy adelantados en la materia. Además, se puede prever con mayor probabilidad de acertar, lo que será eventualmente el inventario final de la flora de Colombia.

En el año de 1940, el profesor Armando Dugand publicó una lista preliminar de las palmas de Colombia, señalando aproximadamente 285 especies y variedades existentes en este país. Sabemos que este número ha aumentado considerablemente con las abundantes colecciones que se han hecho de 1940 hasta la fecha, pues desde entonces el profesor Dugand, y más recientemente el profesor L. H. Bailey de la Universidad de Cornell, no sólo han descrito varias especies y géneros nuevos de palmas colombianas sino que han señalado por primera vez en la flora de Colombia muchas especies que hasta ahora se creían exclusivamente pertenecientes a países vecinos. Vale la pena anotar que el profesor Dugand ha descrito recientemente, de la región de Bahía Solano, en la Costa del Pacífico, una hermosa palmita, la Malortiea pumila, que no sólo era especie desconocida para la ciencia sino que es nada menos que la palma más pequeña del mundo entero. Así, Colombia posee la palma más diminuta y también la palma más elevada del mundo. Esta última es la "palma de cera del Quindío" (Cero- 


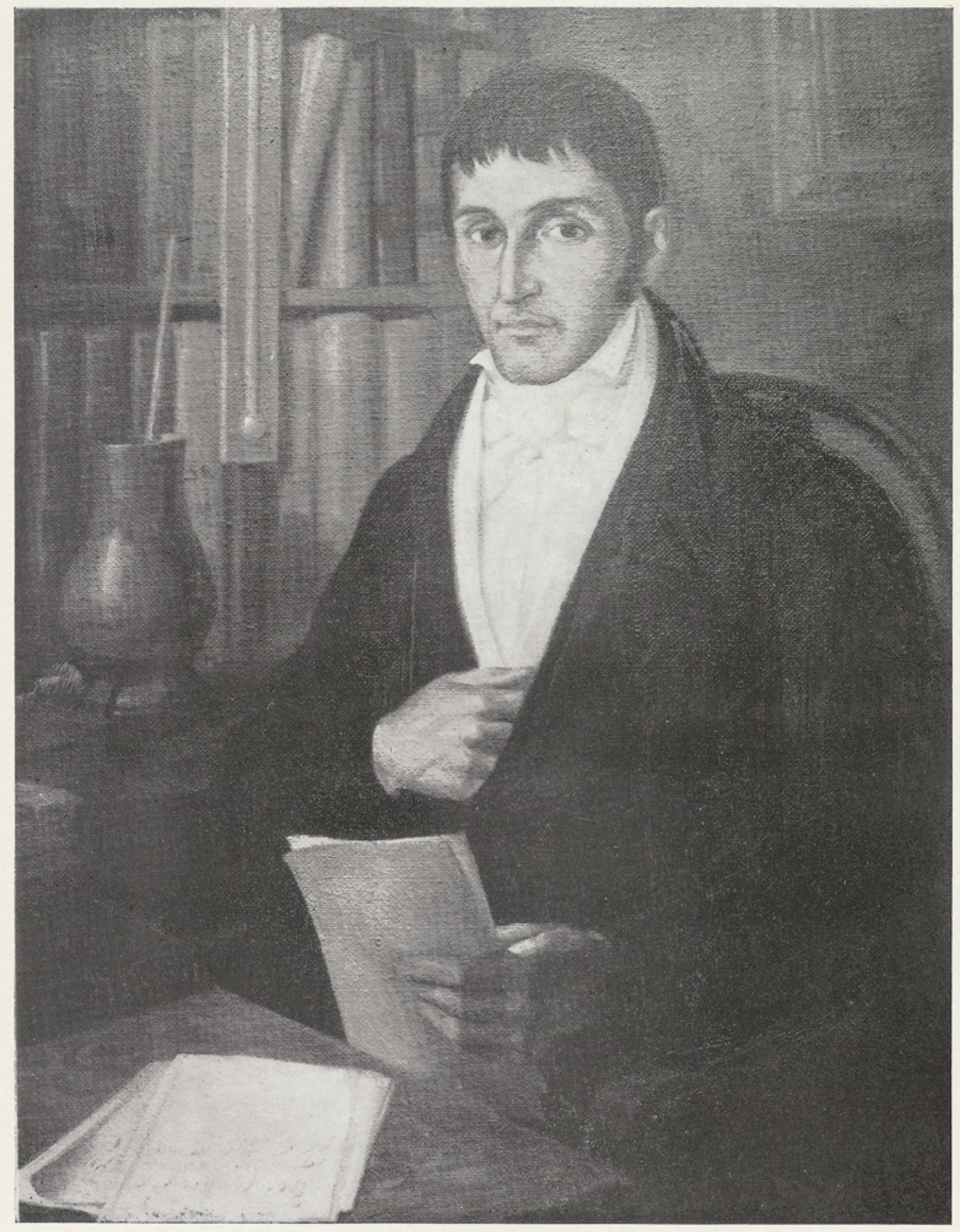

FRANCISCO JOSE DE CALDAS

$$
(1771-1816)
$$

Oleo de Miguel Díaz V., propiedad del Observatorio Astronómico Nacional.

Fotografía tomada por el Dr. H. García Barriga.

(Prohibida la reproducción). 
xylon quindiuense) que fue recientemente escogida, a iniciativa del profesor Dugand, como árbol simbólico de Colombia.

¡Cuántas gratas sorpresas como ésta nos esperan ocultas en las selvas de Colombia! Con más de 300 especies de palmas ahora citadas en su flora, Colombia cuenta con una representación equivalente a la cuarta parte de las palmas conocidas en el Nuevo Mundo y como una duodécima de las del mundo entero.

Debido también a las investigaciones del profesor Dugand, el número de especies de Ficus (higneras silvestres) conocidas en Colombia, que era sólo de 34 en el año de 1941 cuando él comenzó a estu. diar y clasificar los materiales de ese género acumulados en el Herbario Nacional Colombiano, ha aumentado durante los últimos diez años a más de 100. Esto representa un incremento del $300 \%$, el cual es verdaderamente extraordinario aún teniendo en cuenta que la mayoría de los árboles de este género son tremendos gigantes de la selva y que por lo tanto es sumamente difícil coleccionar muestras de ellos. Se ha descubierto, cerca del Salto de Tequendama, una rara especie de Ficus, bautizada por Dugand con el nombre de Ficus tequendamae. Es un árbol de regulares dimensiones y cuyos frutos están cubiertos con una lana de color castaño rojizo, como el pelo de una ardilla, carácter éste de mucho interés en el género. Lo que resulta sorprendente en este caso es que muchos de los naturalistas que han visitado a Colombia - desde Hum. boldt y Bonpland hasta los de la actualidad- y aún los mismos colombianos como Mutis, Caldas y Triana, han hecho colecciones botánicas en la región del Tequendama $y$, sin embargo, no repararon en esta especie tan curiosa, siendo árbol corpulento. Así quedó sin describir hasta el año de 1942, cuando Dugand dio primera noticia técnica de ella en la revista Caldasia.

Si descubrimientos como éste se hacen en los al. rededores de la capital de la República, ; cuántas maravillas no hallaremos en regiones que todavía permanecen inexploradas o poco conocidas!

Podemos citar otro ejemplo de cómo el estudio intensivo y extensivo está aumentando con rapidez la lista de plantas colombianas: el caso de los "frailejones". Estas plantas tan curiosas crecen exclusivamente en los páramos de Venezuela, Colombia y Ecuador, y parece que su centro de diversificación es la Cordillera Oriental de Colombia. El doctor Cuatrecasas se dedicó en años recientes al estudio taxonómico de los frailejones, los cuales pertenecen al género botánico Espeletia. Aunque estas plantas habitan, en gran parte, en páramos que no se hallan lejos de las vías de comunicación o de algunos pueblos andinos y aún de ciudades populosas, podemos decir que ha sido solamente en los últimos diez o doce años cuando hemos logrado adquirir un conocimiento más preciso de este interesante grupo de plantas. Cuando el doctor Cuatrecasas comenzó sus trabajos sobre Espeletia sólo se conocían 12 especies colombianas: actualmente el inventario alcanza a no menos de 43 especies distintas en este país, con la posibilidad de que este número aumente cuando se realicen excursiones a páramos que todavía se hallan inexplorados. Esto representa, en el caso de una de las plantas más típicas de Colombia, un aumento del $350 \%$. Según el doctor Cuatrecasas, la flora de Venezuela cuenta con 27 especies de Espeletia. El mismo investigador ha estudiado otros grupos de plantas colombianas: por ejemplo, antes se citaban de manera muy vaga unas 6 o 7 especies de Cecropia (yarumos o guarumos) de este país. Cuatrecasas hasta la fecha ha descrito 41 nuevas especies de este género y cuenta con algunas otras por describir. Ha descrito también 42 especies de la familia de las Araliáceas, número muy superior al conocido con anterioridad en este país. Triana y Planchon, en su trabajo sobre las Gutíferas, citaban 45 especies de esta familia (exceptuando Vismia y Hypericum); Cuatrecasas ha descrito 86 especies nuevas para la ciencia.

Los minuciosos estudios del padre Lorenzo Uribe en el género Inga y algunas cucurbitáceas de Colombia nos han demostrado que en estos dos grupos de plantas hay también novedades.

Recientemente, en las páginas de Caldasia, el doctor Lyman B. Smith y la doctora Bernice G. Schubert publicaron una monografía de las Begoniáceas que habitan en Colombia. Cuenta esta bella familia de plantas ornamentales con más de 64 especies y variedades en el país, lo cual significa un aumento muy apreciable en el número conocido de representantes colombianos. En el mundo entero se conocen unas 800 especies de Begoniáceas; de manera pues que la flora de Colombia posee aproximadamente el $8 \%$ del total mundial de estas plantas. $Y$ con las nuevas colecciones que se están haciendo ha de aumentar esta cifra porque ahora está ingresando a los herbarios colombianos material nuevo de regiones poco o nada exploradas.

Una de las especialidades del doctor Jesús M. Idrobo, custodio jefe del Herbario Nacional Colombiano en el Instituto de Ciencias Naturales, es la familia de las Marantáceas - los bijaos- tan comunes en las selvas húmedas de los trópicos. Este es uno de los grupos vegetales que más necesitan de estudios taxonómicos minuciosos. Hay en el mundo unas 185 especies reconocidas de Marantáceas. La flora de Colombia, según el doctor Idrobo, contará probablemente con unas 60 a 70 , incluyendo una docena de especies nuevas cuyas descripciones él va a publicar próximamente. Antes de empezar Idrobo sus colecciones de material para el estudio de esta familia, el Herbario Nacional Colombiano tenía solamente cinco especies, o sea menos del $10 \%$ del número de especies que se encuentran en el territorio nacional. El doctor Idrobo se ocupa también de la interesante familia de las Xiridáceas, de la cual sólo existía material representativo de una especie en el Herbario Nacional; 

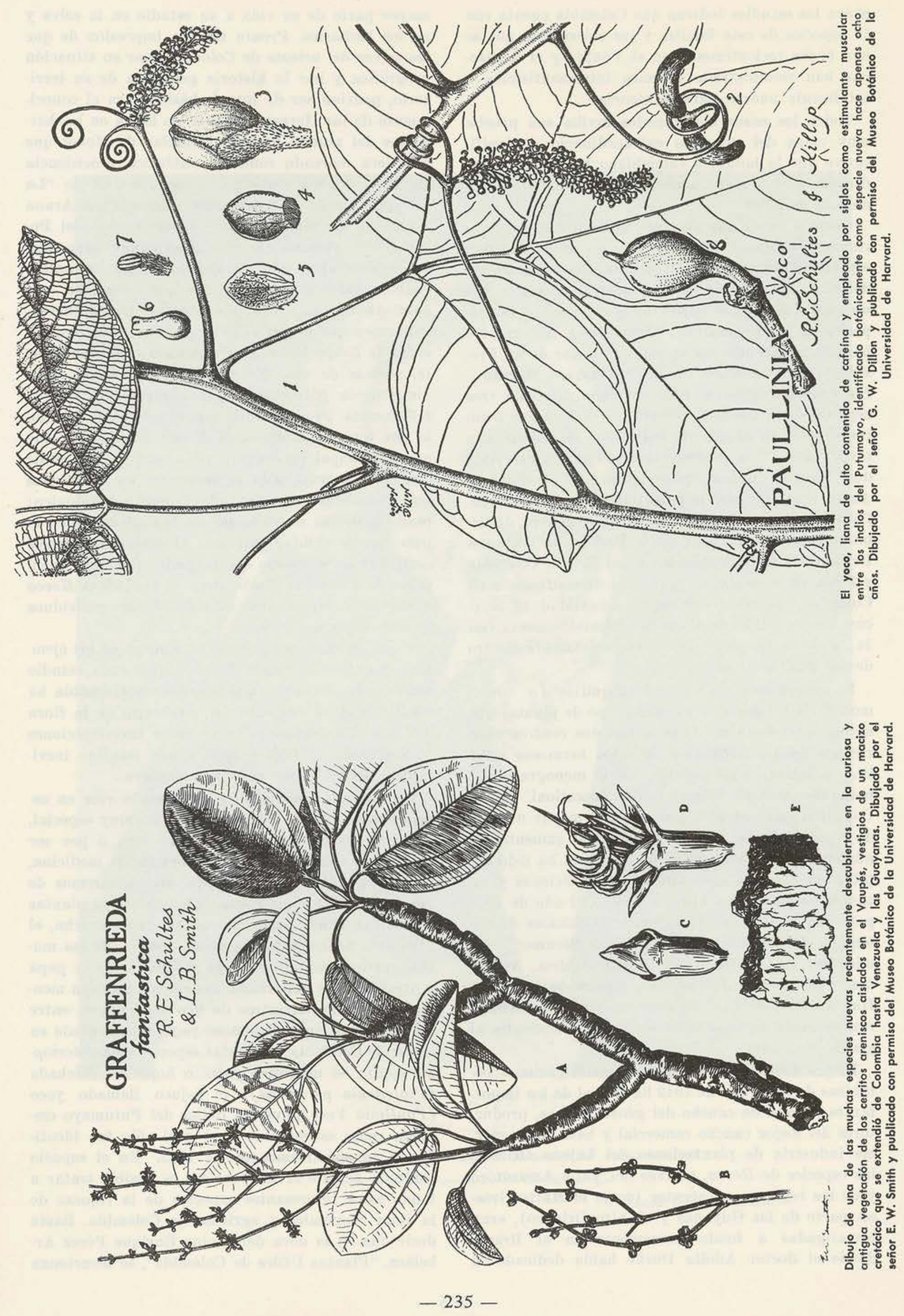


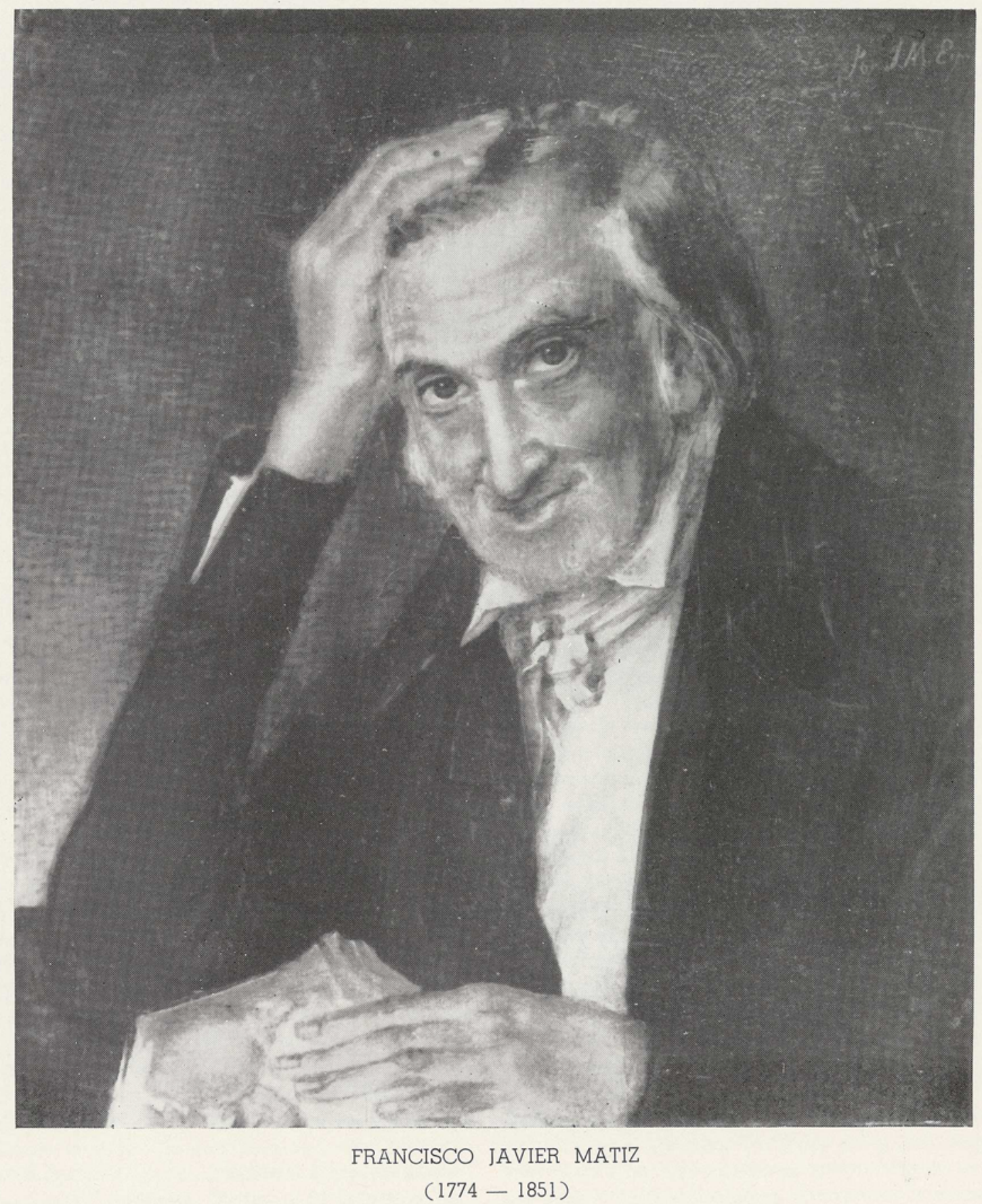

Miniatura en marfil de José María Espinosa, propiedad del Museo Nacional.

Fotografía tomada por el Dr. H. García Barriga.

(Prohibida la reproducción), 
ahora los estudios indican que Colombia cuenta con 17 especies de esta familia y las colecciones que se han hecho recientemente en el Vaupés y el Amazonas han suministrado especies interesantísimas y totalmente nuevas para la ciencia.

Todos los casos mencionados arriba son prueba muy clara del progreso extraordinario y significativo que la botánica colombiana ha hecho en los últimos años y sigue haciendo para beneficio de la ciencia mundial.

Cuando en el año de 1941 empecé mis exploraciones y estudios de la vegetación de Colombia, especialmente en relación con la flora amazónica del país, me interesé en el género Herrania, o sea un grupo de cacaos silvestres muy afines a las especies de cacao común (Theobroma). El género, bautizado hace más de un siglo en honor de un Presidente de Colombia - Pedro Alcántara Herránfue conocido durante todo un siglo por sólo tres especies descritas de Colombia por el botánico francés Goudot en el año de 1844. Casi cien años más tarde, en 1941, el profesor García-Barriga describió dos especies nuevas procedentes del Putumayo. Ahora tengo preparada para publicar una monografía de Herrania y sabemos ya que este género, distribuído desde Costa Rica hasta Bolivia, la Guayana Británica y toda la Amazonía del Brasil, Colombia y Perú, tiene su mayor centro de diversificación en Colombia. Se reconocen en la actualidad 16 especies, de las cuales la flora de Colombia cuenta con 14; y de éstas, siete crecen exclusivamente dentro de los límites de este país.

El género Saurauia - los "moquillos" o "dulumocos" de los Andes- es otro grupo de plantas que me ha interesado muchísimo. Los dos centros americanos de diversificación de estos hermosos arbolitos son México y Colombia. En la monografía del botánico italiano doctor Luigi Buscalioni figura Colombia como el país que posee el mayor número de especies de Saurauia; y aún así el aumento del número de especies nuevas en este país ha sido notable recientemente, debido a las colecciones y estudios hechos en los últimos años. Del año de 1943 para acá he descrito 14 especies adicionales de Colombia. También el doctor Herman Sleumer - exmiembro del Herbario de Berlín-Dahlem, Alemania - ha descrito dos especies nuevas de este país. Hay indicios de que estudios monográficos señalarán aún más especies colombianas pertenecientes al género Saurauia.

El problema principal de mis investigaciones botánicas desde el año de 1942 ha sido el de los importantes árboles de caucho del género Hevea, productores del mejor caucho comercial y base de la enorme industria de plantaciones del Lejano Oriente, las especies de Hevea, nativas del Valle Amazónico y de las regiones adyacentes (como el Matto Grosso, parte de las Guyanas y el Alto Orinoco), eran investigadas a fondo únicamente en el Brasil, donde el doctor Adolfo Ducke había dedicado la mayor parte de su vida a su estudio en la selva y en los herbarios. Pronto tuve la impresión de que las selvas del oriente de Colombia, por su situación geográfica y por la historia geológica de su territorio, podrían ser de interés básico para el conocimiento de las Heveas. En 1940 no había en los herbarios del mundo un solo ejemplar de Hevea que estuviera marcado como de auténtica procedencia colombiana. Sin embargo, desde los días de "La Vorágine" y de la tristemente célebre Casa Arana - con las atrocidades del "infierno verde" del Putumayo- sabíamos que este género cauchífero existe en Colombia, pero ignorábamos por completo cuál o cuáles especies son las que crecen en este país. Ahora, nuestro abundante material de herbario indica que de las ocho o nneve especies reconocidas de Hevea la flora de Colombia cuenta con siete, además de una variedad arbustiva enana cuya distribución parece ser exclusivamente restringida a Colombia. Pero también hemos aprendido que, en lo que toca a Colombia, la Hevea brasiliensis, que es la principal productora de la mejor calidad de caucho comercial, sólo se encuentra en cantidades muy reducidas en el limitado Trapecio Amazónico; pues los demás cauchos que se dan silvestres en el país son de calidad inferior. Al respecto podemos decir que en territorio del Trapecio, que es la única parte de Colombia donde crece la verdadera Hevea brasiliensis, no existen más de 30.000 individuos de esta especie.

Y así, para no multiplicar el número de los ejemplos, podemos resumir diciendo que cada estudio taxonómico realizado últimamente en Colombia ha resultado en el aumento del inventario de la flora del país. La continuación de tales investigaciones botánicas en el futuro tendrá que resultar inevitablemente en cifras cada vez mayores.

La flora de Colombia es sumamente rica en especies vegetales de interés económico muy especial, ya por ser prácticamente desconocidas o por ser muy prometedoras en lo que concierne la medicina, la alimentación o la industria. Mencionaremos de paso solamente unas pocas, tales como las plantas endémicas alimenticias, la curuba, la arracacha, el ulluco, la áchira y varias otras, además de las muchas variedades agronómicas del maíz, de la papa y otras plantas cultivadas. Podríamos también mencionar plantas silvestres de uso tan curioso entre los indígenas como el famoso yagé, representado en el sur de Colombia por varias especies (Banisteriopsis spp.); el narcótico yopo o ñopo del Vichada (Piptadenia peregrina); el bejuco llamado yoco (Paullinia Yoco), que los indios del Putumayo emplean como estimulante y el cual sólo fue identificado taxonómicamenete en 1942. En el espacio limitado de este artículo no me es posible tratar a fondo estos interesantes aspectos de la riqueza de la flora económica y agrícola de Colombia. Basta decir que en la obra del doctor Enrique Pérez Arbeláez, "Plantas Utiles de Colombia", se mencionan 
911 géneros diferentes de plantas que representan probablemente entre 2.000 y 3.000 especies distintas. Tampoco debemos olvidar las muchas plantas ornamentales o curiosas, como varias orquídeas, la maravillosa Victoria regia del Trapecio Amazónico, muchas Aráceas de flores extrañamente conformadas, e infinidad de palmeras enanas que serían un éxito en los invernaderos del exterior.

Es importante recordar que este aumento del catálogo de la flora colombiana es resultado no sólo del descubrimiento de especies o variedades hasta ahora desconocidas, sino también -y en su mayor parte, para decir verdad- del hallazgo en territorio colombiano de plantas que hasta ahora habían sido señaladas únicamente como elementos de las floras de países vecinos. Ultimamente se han publicado varias listas de especies - algunas de éstas descritas hace ya más de un siglo- que por primera vez se registran en la flora de Colombia. Tales hallazgos resultan naturalmente con mayor frecuencia en las colecciones hechas en las regiones limitrofes de la República. Muchas de mis colecciones, por ejemplo, son de las partes de Colombia fronterizas con el Perú - el río Putumayo y el Trapecio Amazónico- o con el Brasil y Venezuela - el alto Río Negro y el Río Guainía-. De estas colecciones resulta un alto porcentaje de plantas ya bien conocidas en el Perú, el Brasil o el Alto Orinoco de Venezuela, pero que todavía no habían sido coleccionadas en territorio de Colombia. Lo mismo sucede con otras colecciones de regiones cercanas a las fronteras, sobre todo en el oriente del país, como la que el doctor Paul H. Allen hizo en el río Vaupés y el río Papurí. La explicación es sencilla: tanto las partes amazónicas del Perú y del Brasil, como la hoya del Orinoco y del Guainía de Venezuela han sido mejor exploradas que los llanos y las selvas orientales y sureñas de Colom. bia. Sin temor a exageración podemos decir que muchas regiones de Colombia ofrecen campos vírgenes de los más importantes y fascinantes en el mundo tropical desde el punto de vista de las ciencias naturales. Me refiero en particular a las hoyas del Amazonas y del Orinoco, a la cuenca del Catatumbo en el nordeste, y a las regiones del Chocó y la Costa del Pacífico hasta Nariño.

En 1949, el doctor Alvaro Fernández, botánico en el Instituto de Ciencias Naturales, hizo un viaje de recolección a lo largo de la Costa del Chocó, patrocinado por la Marina de Guerra Colombiana. Sus colecciones son muy ricas en especies y géneros de Centro América, hasta ahora no representadas en el Herbario Nacional. Además del descubrimiento de especies y géneros nuevos para Colombia, se han registrado en los últimos años hasta familias nuevas, como por ejemplo las Velloziáceas y las Rapateáceas, que eran absolutamente desconocidas en el país.

Hace ya precisamente un siglo que andaba el botánico Richard Spruce explorando el alto Río
Negro, el río Vaupés brasileño y el Guainía, Atabapo y Alto Orinoco en la frontera colombo-venezolana. Abnegado y dedicado a su ciencia con entusiasmo sin límite, Spruce merece que se le coloque entre los exploradores más eficientes de todos los tiempos. Reunió una vasta colección de plantas de esas regiones. En su viaje por el Vaupés brasileño llegó hasta el punto llamado Tauareté o Yavaraté, en la boca del río Papurí, donde hoy unen sus fronteras el Brasil y Colombia. Subió y exploró por poco tiempo el Papurí, cuya banda izquierda pertenece hoy a Colombia. También tocó en territorio colombiano en algunos lugares del Río Negro arriba de la Piedra del Cocuy, en el río Guainía arriba de la boca del Casiquiare y así mismo en Maipures, sobre la banda izquierda del Orinoco. En un artículo publicado en Caldasia hace tres años, el profesor Dugand dio a conocer las localidades visitadas por Spruce en territorio que hoy es de Colombia, pero que todos los botánicos habían tenido por brasileñas o venezolanas. Como en aquellos tiempos no estaban definidos los lírnites políticos del Brasil, Colombia y Venezuela, es imposible determinar la localización exacta de algunos ejemplares que Spruce coleccionó en las riberas de aquellos ríos que hoy sirven de fronteras a estos países. Sólo cuac lo en la colección se menciona un lugar determinado puede saberse con exactitud si dicho lugar está ubicado hoy en territorio de aquellos países o en el de Colombia.

Tanto en las colecciones de Allen como en las mias hechas en territorio colombiano adyacente al Brasil y Venezuela han aparecido plantas rarísimas que figuraban solamente en las colecciones que Spruce hizo hace un siglo. Naturalmente, el redescubrimiento de una planta rara, después de tanto tiempo, causa al botánico una satisfacción tanto o más profunda que el descubrimiento de una especie o de un género nuevo.

Ahora sabemos que las regiones de la Comisaría del Vaupés que se extienden desde los alrededores de Mitú hasta la frontera con el Brasil en el mismo río Vaupés, y hasta Venezuela en el río Guainía, son geológica y fitológicamente iguales a las que baña el alto Río Negro en el Brasil, donde Spruce hizo el grueso de sus colecciones en el período de 1850 a 1854 . Las colecciones recientes en aquellos territorios de Colombia son, hasta el momento, muy insignificantes ante la voluminosa obra de Spruce; pero, sin embargo, me atrevo a decir que, con el tiempo, la gran mayoría de las especies recogidas por el gran explorador británico en el Río Negro y el Vaupés brasileño se encontrarán también en la flora del Vaupés colombiano. Al calcular la riqueza de la flora de Colombia esta probabilidad no debe despreciarse; lo cual significa que todavía quedan en aquellas selvas, por registrar como plantas nuevas para Colombia, unas 1.200 a 1.600 especies y variedades que hasta ahora se han tenido por exclusivamente brasileñas $o$ venezolanas. 


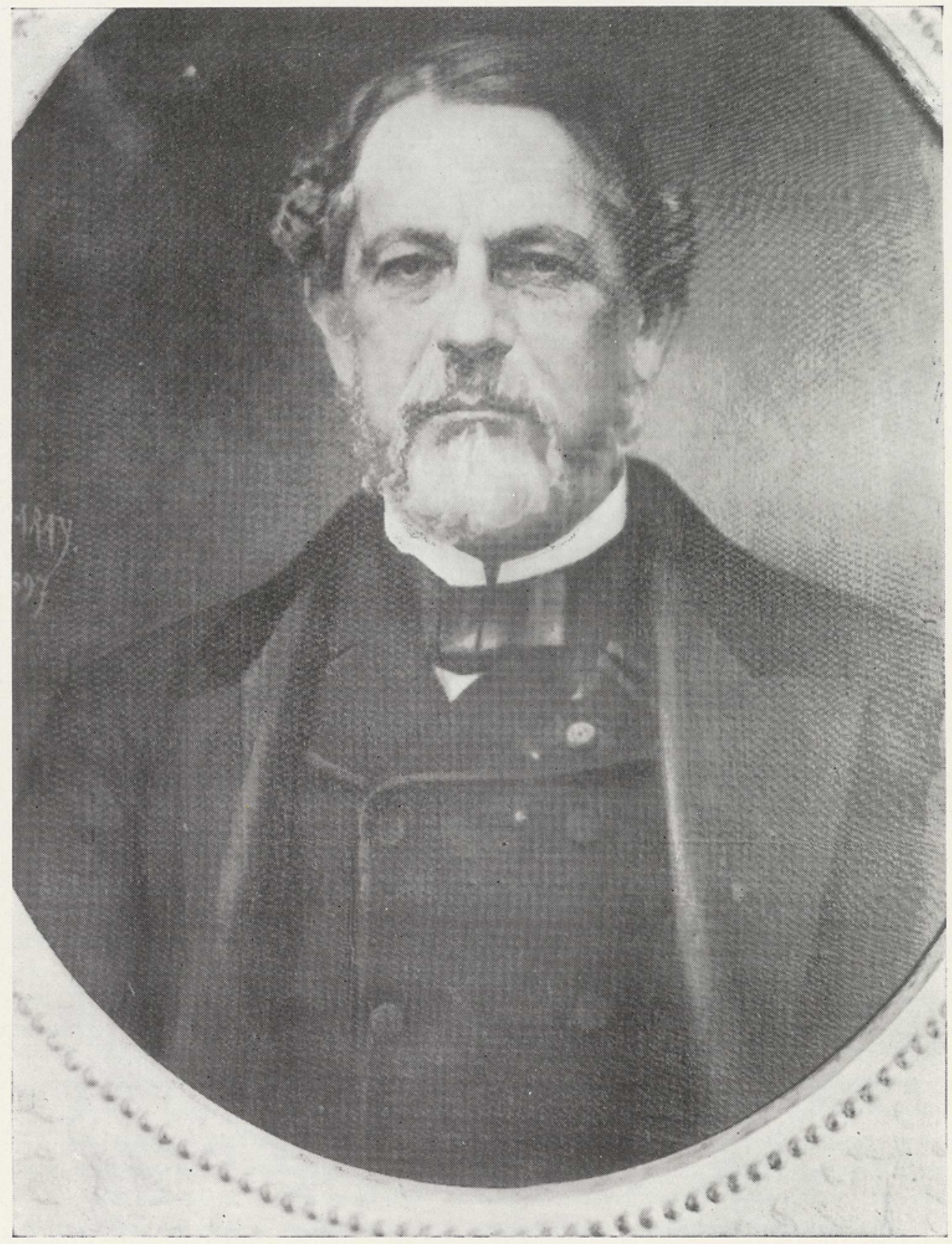

\section{JOSE JERONIMO TRIANA}

$(1828-1890)$

Oleo de Epifanio Garay, propiedad del Instituto de Ciencias Naturales.

Fotografía tomada por el Dr. H. García Barriga.

(Prohibida la reproducción). 
Es sumamente interesante saber que, hace ya un siglo, Spruce reconoció la riqueza de la flora de la inmensa selva del oriente de Colombia. Desde el Río Negro en el Brasil escribió una carta al gran botánico inglés George Bentham en la cual le decía: "Ultimamente me he ocupado en el cálculo del número de especies aún desconocidas en la extensa selva amazónica, desde los raudales del río Orinoco hasta las serranías del Matto Grosso. Si tomo como base el hecho de que son nuevas aproximadamente la mitad de las plantas que he hallado al trasladarme en la distancia de un grado de latitud o de longitud, y si consideramos que lo que hoy se halla explorado -muchas veces inadecuadamente- por Humboldt, Martius, yo, y otros, son apenas fajas angostas de terreno, deberian quedar todavía sin descubrir unas 50.000 o aún 80.000 especies. A cualquiera otra per sona este cálculo parecerá muy extravagante, porque aún el mismo Martius (si mal no recuerdo) opinó que las selvas del Amazonas son pobres en número de especies... Pasé más o menos quince días en el punto más alto de mi penetración al río Vaupés, el raudal de Javarité. El tiempo era muy lluvioso y mi experiencia me enseña que durante el período lluvioso son muy pocos los árboles selvá ticos que florecen. Pero, cuando llegó la fecha de regresar a Ipanoré... mejoró el tiempo y mientras navegábamos río abajo entre las piedras de los raudales que allí obstruyen el curso de las aguas, bien recuerdo yo cómo, en una mañana de sol, las riberas del río se habían cubierto de flores como por obra de magia, y cómo pensaba yo: 'Allá va una nueva Dipteryx, allá una nueva Qualea'... hasta que, no pudiendo aguantar más, me tapé la cara con las manos y me resigné a la triste idea de que tenía necesariamente que abandonar todas esas be llezas... De aquel sitio hacia el occidente [es decir, la región colombiana], se puede suponer con seguridad que casi todo es nuevo para la ciencia, y no cabe la menor duda de que el territorio al oriente de Pasto y Popayán, donde nacen los ríos Caquetá, Vaupés y Guaviare, ofrecen al botánico un campo tan rico como cualquiera en Suramérica. Pero, res. pecto de la posibilidad de llegar a esa región, tengo informes de que sería necesario atravesar páramos [sic] de un carácter sumamente montañoso e inhóspito y luego arriesgarse entre indios salvajes y peligrosos, de manera que temo que la exploración de ese territorio tengo que dejarla a alguien más joven y fuerte que yo".

Apenas estamos iniciando nuestra penetración en dichas regiones y se está comprobando ya que Spruce tenía mucha razón, pues son un verdadero emporio de novedades para la ciencia botánica.

Pero no es necesario que consultemos las colecciones antiguas hechas en países vecinos para de mostrar que hay todas las probabilidades de que la flora de las regiones limítrofes de Colombia es muchísimo más rica de lo que parece a primera vista. Podríamos dar ejemplos más recientes, tales como las grandes colecciones hechas en el Departamento de Loreto del Perú durante los últimos treinta años por el lamentado doctor Guillermo Klug. Si quisiéramos exigir otro ejemplo moderno, podríamos hablar de los miles de plantas que el doctor Llewelyn Williams coleccionó hace unos veinte o veinticinco años en la región del Amazonas que se extiende entre Iquitos, Perú y Leticia, Colombia, como también hace unos diez años en el Guainía y el Alto Orinoco de la frontera colombovenezolana. Podríamos consultar las colecciones hechas en el occidente del Estado de Amazonas del Brasil por los botánicos brasileños, especialmente por el doctor Ducke y el señor Ricardo Froés, miembros del muy activo Instituto Agronômico do Norte en Belém do Pará. El trabajo de estos investigadores ha demostrado que cerca de las fronteras de Colombia con el Brasil, Venezuela y el Perú, existe un sinnúmero de plantas que todavía no están registradas en el catálogo de la flora colombiana. Mirando ahora hacia los lados del istmo del Darién en el noroeste de Colombia, no cabe ninguna duda de que a medida de que vayamos explorando la vegetación del norte del Chocó, encontraremos un número considerable de especies que hasta ahora se han considerado como exclusivas de Centroamérica, particularmente elementos de la muy bien conocida flora panameña.

Otra fuente de especies botánicas por incluír en el inventario de la flora colombiana $-\mathrm{y}$ el caso es verdaderamente curioso- la constituyen aquellas plantas descritas a base de material coleccionado en territorio colombiano pero que, por una razón u otra, han sido atribuídas erróneamente a otros países. Tal vez el ejemplo más significativo es el caso de muchas plantas del ilustre botánico y explorador alemán, Karl Friedrich von Martius. En los años de 1819 a 1820 von Martius llevó a cabo exploraciones muy extensas en el Brasil, trabajando con especial energía en el valle del Amazonas. Luego regresó a Alemania y se dedicó a editar con la ayuda de una verdadera constelación de botánicos europeos de gran renombre una obra monumental: La F'lora Brasiliensis. Este estudio florístico sigue siendo hasta el presente una obra necesarísima para todo botánico que se ocupe de la flora suramericana, y es absolutamente indispensable para todo estudio de la vegetación amazónica. Pues bien, hace nueve años el profesor Dugand demostró en un artículo sobre palmas de la Amazonía Colombiana que Martius había penetrado largo trecho en territorio que actualmente pertenece a Colombia. Sucedió que, habiendo entrado Martius por el Japurá, que es el mismo río llamado Caquetá en Colombia, lo subió en enero de 1820 hasta los raudales de Araracuara, es decir, varios centenares de kilómetros dentro del territorio colombiano. En un lugar llamado Cupatí coleccionó un gran número de plantas, muchísimas de ellas nuevas entonces para la ciencia. Resulta que el tal Cupatí es el mismo 
sitio que se conoce hoy con el nombre de La Pedrera, en territorio de Colombia. Martius coleccionó también en varios lugares entre Cupatí y Araracuara, haciendo una labor de excepcional rendimiento botánico. Todas las plantas obtenidas por él en el largo trayecto entre la boca del Apaporis (en la frontera actual de Colombia y el Brasil) y el Araracuara, se señalan en la Flora Brasiliensis y en otras obras como procedentes del Brasil y esto se debe a que 130 años atrás nadie se preocupaba de límites internacionales en aquellas regiones cubiertas de densas selvas, desiertas o escasamente habitadas por indios salvajes. Además, también es cierto que el entonces Imperio del Brasil llevaba sus pretensiones territoriales precisamente hasta la cadena de cerros del Araracuara, de manera que el error geográfico no se puede de ningún modo atri buír a ignorancia de Martius.

En los herbarios de Bruselas $y$ de Munich he consultado muchos de los ejemplares llevados del Caquetá por von Martius; pero, aunque son numerosos, sería difícil anticipar cuántas son las especies que debemos agregar a la flora de Colombia. Dugand, por ejemplo, ha señalado unas 40 especies de Leguminosas y unas 18 palmas recolectadas en territorio colombiano por von Martius y atribuídas erróneamente el Brasil. Si en sólo dos familias hay cerca de 60 plantas cuyo status geográfico es colombiano y no brasileño, se puede tener una idea bastante aproximada de lo que será el número total, cuando se examinen las colecciones hechas por Martius en el Caquetá colombiano.

Algunas de las palmas colectadas por von Martius son, como lo indica el profesor Dugand en sus estudios, no solamente originarias topotípicamente del territorio colombiano sino que nunca más se han vuelto a coleccionar desde que el gran explorador alemán visitó la región hace 130 años, resultando así de una importancia única para los estudios monográficos. Varias otras de las especies rarísimas de la expedición de von Martius al Caquetá (como, por ejemplo, el muy curioso ceibo enano de metro y medio de altura, Bombax coriaceum, proveniente del Araracuara) están volviéndose a descubrir ahora en otras localidades de la Amazonía Colombiana.

Aunque el insigne von Martius nunca sospechó que había penetrado cerca de 400 kilómetros en territorio que más tarde sería de Colombia, sí nos dejó una herencia botánica de gran valía e inesperada para nosotros. Casi un siglo y medio después de sus hazañas quisiéramos tener la oportunidad de recorrer las márgenes del Caquetá, entre el Araracuara y la frontera del Brasil, para volver a integrar todo lo que nuestro antecesor llevó a cabo con tanta dedicación y esfuerzo.

Ahora pues, terminada nuestra inspección de los modos por los cuales se puede esperar con seguridad que aumente el censo de las plantas que existen silvestres en el territorio de Colombia, regresaremos al tema principal de este artículo, a saber: la riqueza de la flora colombiana. ¿Cuántas especies diferentes existen en este país? Arriba he dicho que, en mi concepto, Colombia posee la flora más rica de todo el Nuevo Mundo, tanto en número de especies como en diversidad de ecología. Examinaremos esto:

¿Qué opinan acerca de la riqueza de la vegetación de Colombia los botánicos bien familiarizados con la flora de este país? En relación con esto he es. crito a varios especialistas pidiéndoles su concepto. El profesor Dugand opina que el inventario total de la flora colombiana puede llegar a cerca de 40.000 especies, contando no sólo las fanerógamas sino también las criptógamas vasculares (helechos, musgos, etc.). El doctor Cuatrecasas, quien ha recogido durante sus exploraciones en distintas partes de Colombia más de 24.000 ejemplares y ha descrito 530 especies y $\mathbf{5}$ géneros nuevos, me escribe que en su concepto la flora colombiana comprende unas 25.000 plantas fanerógamas distintas.

Antes de dar mi concepto propio sobre este interesante asunto, me gustaría volver atrás para considerar mi opinión de que la flora de Colombia es quizá la más rica de las Américas. Como bien lo podemos apreciar, la diversificación de las plantas causada por la evolución biológica depende en parte muy grande de la diversificación del habitat o del ambiente causada por modificaciones geológicas y climáticas. El estudio de los habitats y de la relación de las plantas con su ambiente se llama ecología, y aunque casi siempre esta rama de la botánica se halla menos desarrollada que la taxonomía, es una verdad axiomática que sólo cuando se desarrollan simultáneamente los estudios taxonómicos, ecológicos y fitogeográficos puede resultar una investigación bien profundizada $\mathrm{y}$ aprovechable.

Aunque en Colombia falta mucho en materia de estudios ecológicos y fitogeográficos, siempre han aparecido varias obras especializadas dedicadas a estas disciplinas. Podemos por lo tanto decir sin peligro de equivocarnos que, debido a sus condicio nes geológicas y climáticas especiales, Colombia tiene, entre los países americanos, más zonas de vegetación diferentes. Así como esta República es en lo humano una colección de grupos étnicos bas. tante diversos, cada uno un tanto diferente del otro, también puede considerarse el país, visto con los ojos de un botánico, como un conjunto de vegetaciones distintísimas. Imaginemos un mapa fitogeográfico de Colombia. Tendríamos en primer término la Cordillera de los Andes que, en la parte extrema sur-occidental del país se ramifica en dos cadenas, luégo en una tercera. De esta triple columna vertebral del país salen varias estribaciones menores. No sólo cada estribación principal y cada ramificación secundaria tiene su flora más o menos diferente, sino que también sucede que las faldas occidentales suelen ser en su vegetación bastante distintas de las orientales. Más importante todavía -y esto es cierto para todo país monta- 


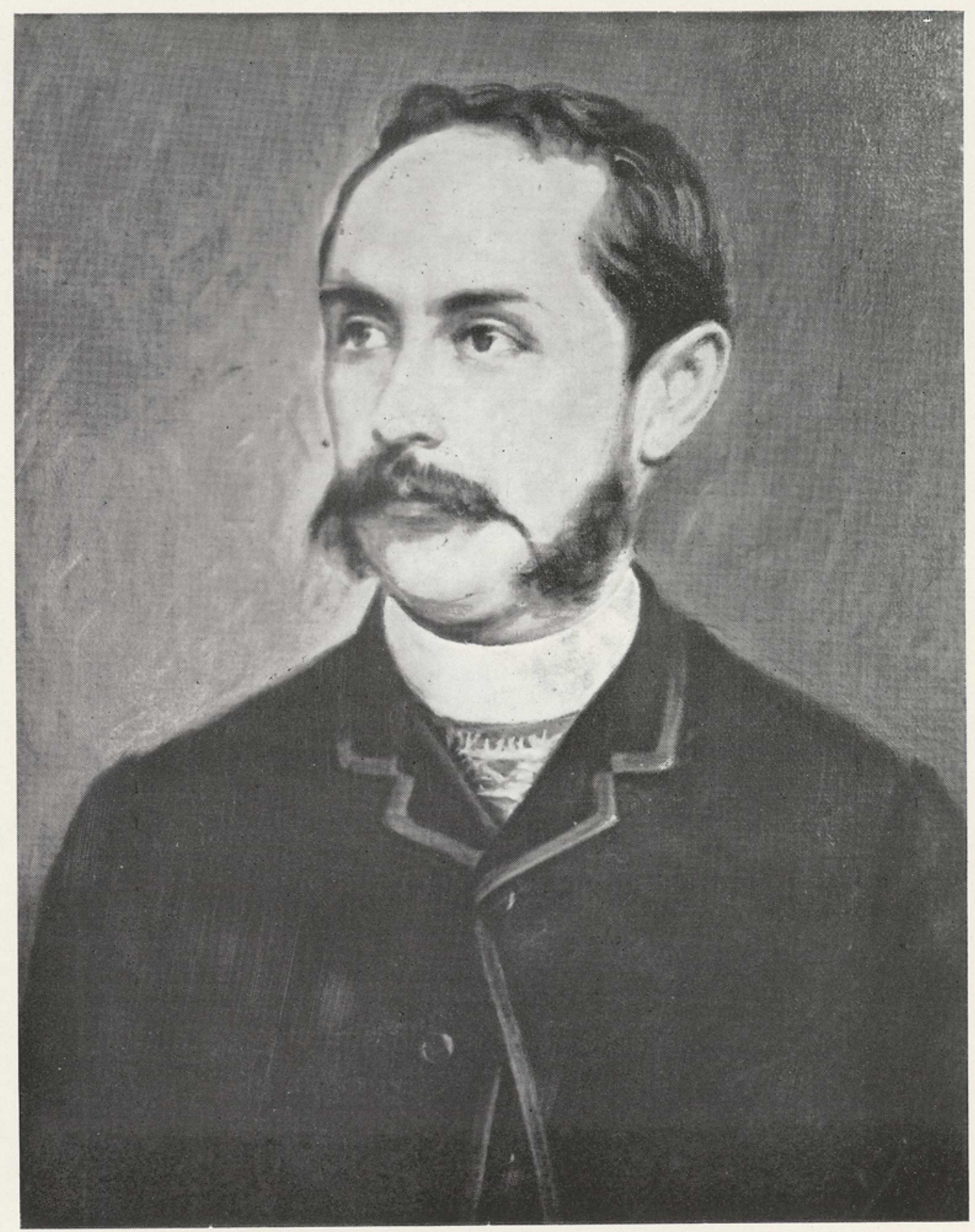

SANTIAGO CORTES

$(1854-1924)$

Oleo de propiedad del Instituto de Ciencias Naturales.

Fotografía tomada por el Dr. H. García Barriga.

(Prohibida la reproducción). 


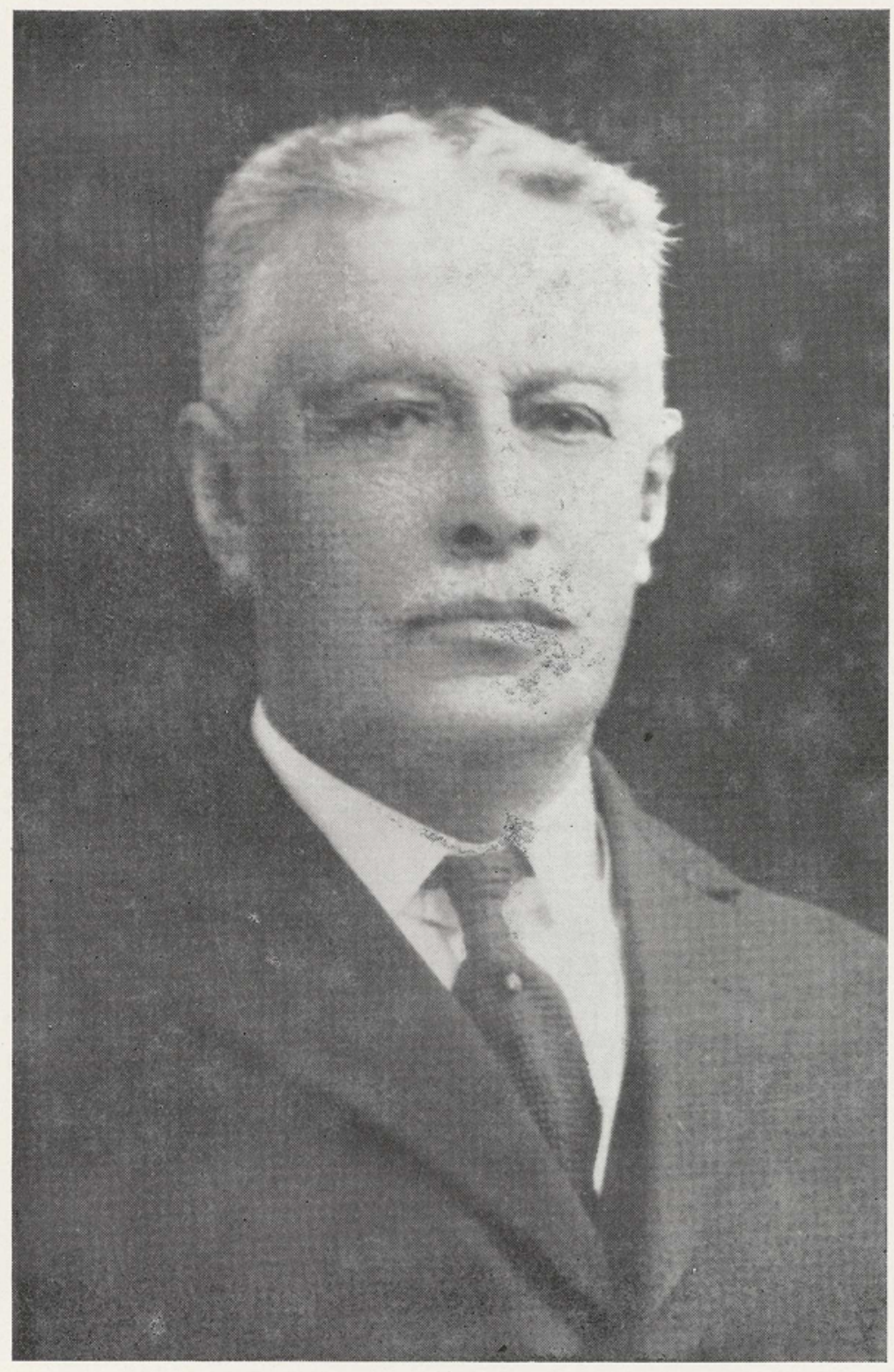

\section{CARLOS CUERVO MARQUEZ}

$(1857$ - 1930)

Fotografía gentilmente suministrada por la señorita Teresa Cuervo Borda, Directora del Museo Nacional.

(Prohibida la reproducción). 


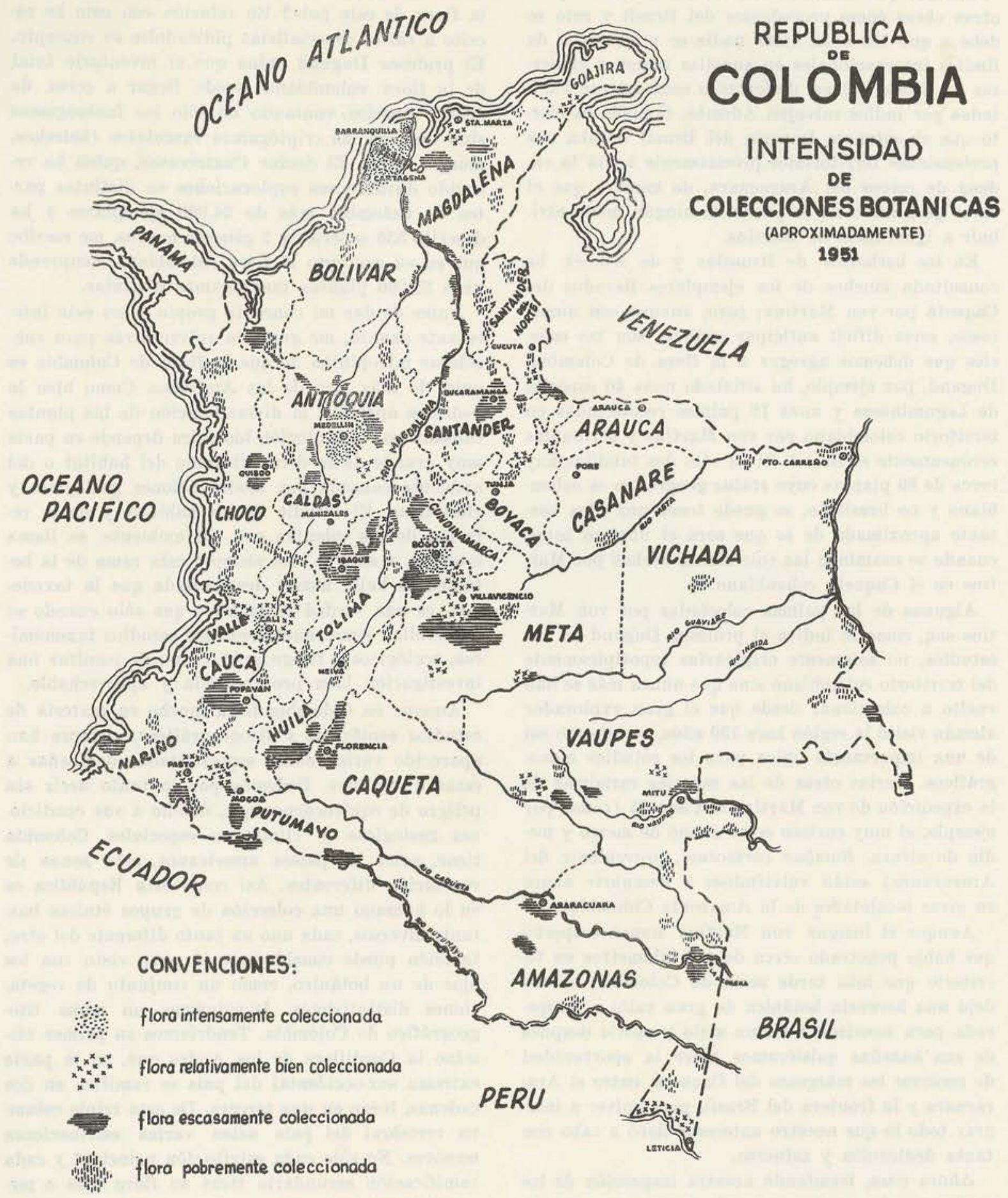


ñoso- estas cordilleras andinas están divididas en varios pisos altitudinales, cada uno muy diferenciado de los otros en su composición florística. Después de los Andes, tal vez las divisiones que más nos llaman la atención son dos: primero, los Llanos Orientales, o sea la hoya colombiana del Orinoco, y segundo la inmensa selva amazónica, que forma la tercera parte del área territorial de la República. Luégo podemos citar como vegetaciones completamente distintas la de las dos costas marítimas: la del Caribe con sus innumerables plantas tropofíticas y sub-xerofíticas; y la del Pacífico con sus densas selvas húmedas, tan aisladas de las demás selvas higrofilas del país. La península de La Guajira podría también considerarse como un extremo de vegetación influída por la aridez, que hace que su territorio sea en gran parte casi un desierto.

La hoya del Magdalena, ocupando una posición estratégica entre las ramificaciones de los Andes, forma otra zona de vegetación con varias sub-zonas. $\mathrm{Y}$ no podemos olvidar la muy interesante cordillera de Baudó, en el Chocó, que, además de sus especies propias, alberga muchas plantas originarias de la América Central. Tampoco podemos dejar de mencionar los numerosos macizos montañosos aislados de Colombia que, habiendo tenido una historia geológica independiente en cierto modo de la de los Andes, sostienen una flora más o menos autóctona y endémica en gran parte; de estos macizos, probablemente los ejemplos más llamativos son la majestuosa Sierra Nevada de Santa Marta, que se yergue a orillas del Mar Caribe, y la Cordillera Macarena, que semeja una isla montañosa en medio de los Llanos. Por último tenemos que agregar los cerros o serranías de arenisca que se encuentran aislados y dispersos por toda la Amazonía Colombiana, pero especialmente en el Vaupés y el Caquetá; y los numerosos cerros o peñones graníticos del Guainía, Río Negro, Inírida, bajo Guaviare y Alto Orinoco. Los primeros, de edad cretácica, representan vestigios de un macizo que antiguamente era continuo con las montañas del sur de Venezuela y de las Guayanas y conservan actualmente una flora extraña, relacionada con la de aquellas remotas cordilleras; los segundos, de edad precámbrica, se relacionan en su flora con la del antiquísimo "escudo brasileño".

La más pequeña división política de Colombia, el Departamento del Atlántico, con sólo 3.470 kilómetros cuadrados, o sea $0.3 \%$ de la superficie total del país, tiene según el profesor Dugand, quien se ha dedicado con preferencia al estudio de su florà, aproximadamente 900 especies de plantas leñosas distribuídas en una regetación sorprendentemente variada a pesar de las condiciones semi-áridas del clima. Esa región de área tan reducida relativamente y cuya mayor altura no excede de 520 metros presenta zonas de vegetación que varían desde los bosques tropófilos de transición, que cubren la región suroccidental del Departamento, hasta los espinares entecos y áridos del nordeste y oriente, y entre estos dos extremos hay otras zonas de vegetación, inclusive la que caracteriza los grandes pantanos de la orilla del río y la de los manglares del litoral.

La variadísima topografía y lo heterogéneo de la historia geológica de Colombia, dejan impresa su marca indeleble en la flora. El resultado es una diversificación extraordinaria en las plantas. Porsupuesto que algunas especies, relativamente pocas en realidad, se hallan representadas sobre vastas extensiones $y$ se encuentran en varias zonas de vegetación; pero no cabe duda de que la gran mayoría de los elementos de la flora de Colombia son endémicos en una o cuando más dos zonas restrictas; y una parte considerable es aún más restringida en su distribución geográfica, siendo endémica en un solo macizo, una sola vertiente y aún un solo valle de reducidas dimensiones. Cuando así se entiende el problema, se puede apreciar fácilmente la verdadera riqueza florística de Colombia.

La riqueza de la flora colombiana tiene también paralelo en la fauna ornitológica. Es muy interesante anotar que se han registrado ya para este país 2,327 especies y sub-especies de aves, que representan 1.474 especies diferentes. Estas cifras, publicadas hace dos años por el doctor Rodolphe Meyer de Schauensee en las páginas de Caldasia, han tenido desde entonces un aumento considerable según me informa el profesor Dugand, (*) hasta el punto de que la fauna ornítica de Colombia ha resultado ser más rica y variada que la del Brasil, cuyo territorio es siete y media veces mayor que el de Colombia. Oliveira Pinto registró en aquel país solamente 2.299 especies y sub-especies en 1944 .

Ahora bien, considerando tanto el área total de Colombia (1.138.205 kilómetros cuadrados), como su topografía tan extraordinariamente complicada y sus climas tan variados, tal vez podemos hacer una provechosa comparación con la riqueza vegetal de algunos otros países de la América Tropical. Recientemente, el doctor Paul C. Standley ha publicado la flora de Costa Rica. Este pequeño país vecino cuenta con 59.000 kilómetros cuadrados y su flora, riquísima por cierto, comprende 6.085 especies de helechos y fanerógamas. Actualmente se está publicando la flora de Guatemala, país cuya superficie es de 108.600 kilómetros cuadrados. Los autores de la "Flora de Guatemala", el doctor Standley y el doctor Julián Steyermark, calcularon para ese país un total de 9.000 especies. Se ve claramente, por lo tanto, que un país del tamaño de Colombia, diez veces más extenso que Guatemala y fitogeográficamente muchísimo más complejo y variado, puede tener un número de especies mayor que lo que indica la simple proporción de las

(*) Véase el segundo párrafo del artículo "Notas Ornitologicas Colombianas" que publica el profesor Dugand en la página 157 de esta misma Revista. 
respectivas áreas territoriales. Según el doctor J. Francis Macbride, quien está escribiendo la "Flo. ra del Perú", hay probablemente unas 10.000 especies diferentes de plantas en aquel país, cuya superficie territorial es de 1.121 .000 kilómetros cuadrados.

Hagamos ahora un cálculo basado objetivamente en el Herbario Nacional Colombiano que, como ya se dijo arriba, contiene hasta la fecha material representativo de 10.300 especies diferentes. Consideremos también que hay muchísimas especies colombianas que se hallan en los herbarios de Europa y los Estados Unidos, y que, por los pocos años de fundado el Herbario Nacional Colombiano, no están todavía representadas en éste. Después de estu. diar las distintas regiones de Colombia, considerando la intensidad relativa de las colecciones hechas en cada una de ellas, yo calculo que las especies colombianas representadas en los distintos herbarios del mundo, inclusive el Nacional, alcanzan a entre una cuarta y quinta parte del total de especies existentes en el país. Aunque carezca totalmente de significación científica, resulta gráfico presentar una estadística en la siguiente forma: el Herbario Nacional Colombiano contiene 10.300 especies diferentes representadas por cerca de 35.000 ejemplares, lo cual da una proporción de una especie por cada 110 kilómetros cuadrados o sea un ejemplar de Herbario por cada 32 kilómetros cuadrados de la República. No importa desde qué punto de vista miremos el horizonte botánico de Colombia; la conclusión inevitable será de que apenas hemos comenzado la investigación de la flora de este gran país.

Considerando, pues, el hecho de que (1) durante los últimos quince años la intensa exploración botánica de Colombia ha comenzado a enseñarnos la magnitud insospechada de la flora del país; (2) cada grupo de plantas colombianas recién estudiado por especialistas ha resultado en aumento considerablemente del número de especies que lo componen; (3) las regiones limítrofes, en las cuales se encuentran muchísimas plantas que hasta ahora han sido señaladas únicamente en países vecinos, se hallan prácticamente inexploradas en su mayor parte; (4) falta conocer la vegetación de varias regiones extensas en el interior mismo del país, como también la de algunos macizos montañosos donde el grado de endemismo es alto; y por último, basando también mi concepto en lo que se sabe de las vegetaciones de otros países tropicales del continente americano, expreso la opinión de que el inventario de la flora de Colombia alcanzará por lo menos a 50.000 especies de plantas, contando solamente las fanerógamas. Si contamos las criptógamas - aún las vasculares únicamente- cuyo estudio es apenas embrionario en comparación con el que hemos dedicado a las fanerógamas, el número aumentará de manera muy considerable. En todo caso, mi predicción sobrepasa a la del más optimista de los colegas consultados, cuyas opiniones cito más atrás.

¡50.000 especies diferentes! La mayor parte de ellas aún desconocidas o no halladas todavía en el territorio de Colombia. Muchísimas de ellas rarísimas en las colecciones, o sumamente extrañas por su aspecto o sus caracteres morfológicos. ¿En qué ciencia y en qué otro país del mundo existe un estímulo más bello e irresistible que este de explorar los arcanos botánicos de Colombia?

Richard Spruce, el explorador de pluma poética, sentía verdaderamente el placer y la satisfacción que resulta de dedicar la vida a la ampliación de nuestros conocimientos botánicos. En una carta escrita hace un siglo en el corazón de la selva amazónica y dirigida a un amigo en Londres, decía :

"Luégo hay ese placer grandísimo entre todos los placeres que le tocan al naturalista, a pesar de que algunos -que anteponen a todo la utilidad práctica- se empeñan en desestimarlo; me refiero al descubrimiento de nuevas especies, que es como llenar vacíos en el mapa de la naturaleza, y, en algunos casos, como poblar las áreas desiertas de ese mapa".

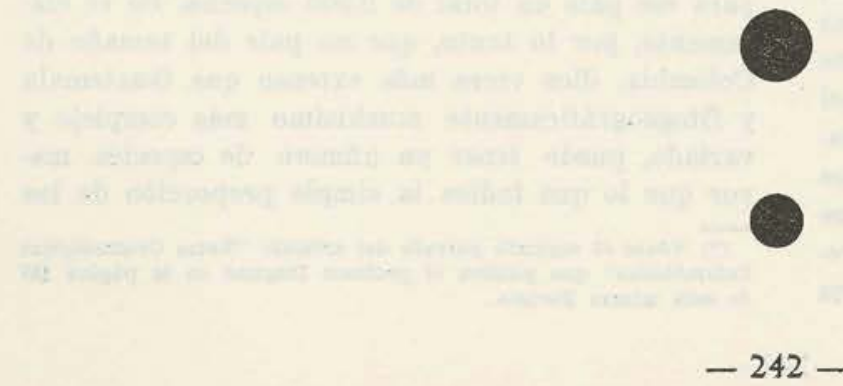

